\title{
AVALIAÇÃO QUALITATIVA DO LEITE PASTEURIZADO TIPO A, B, E C COMERCIALIZADO EM NATAL, RN
}

\author{
C.G.F. Araújo ${ }^{1}$, A.H.N. Rangel ${ }^{1}$, H.R. Medeiros ${ }^{1}$, \\ C.G. Mendes ${ }^{2}$, M.R. Abrantes², E.S. Sousa², J.B.A. Silva²
}

${ }^{1}$ Universidade Federal do Rio Grande do Norte, Unidade Acadêmica Especializada em Ciências Agrárias, RN 106, km 3, Distrito de Jundiaí, CEP 59280-000, Macaíba, RN, Brasil. E-mail: cynthiazootecnista@hotmail.com

\author{
RESUMO
}

\begin{abstract}
As amostras analisadas eram de oito marcas comerciais diferentes de leite pasteurizado comercializado na Cidade de Natal, RN. Para cada marca foram coletadas amostras de três diferentes datas de processamento, totalizando vinte e quatro amostras, sendo uma marca do tipo A, três do tipo B e quatro do tipo C. Foram realizadas análises microbiológicas (bactérias aeróbias mesófilas, coliformes totais e coliformes termotolerantes) e físico-químicas, estas através do aparelho de análise ultrassônica de leite, Ekomilk Total ${ }^{\circledR}$, sendo determinadas: gordura, extrato seco desengordurado, densidade, proteína, ponto crioscópico e lactose. As amostras do leite tipo A apresentaram resultados fora dos padrões nas análises microbiológicas e físico-químicas. O leite pasteurizado tipo B obteve duas marcas com contagens microbiológicas em desacordo com a legislação. O leite pasteurizado tipo $\mathrm{C}$ foi o que apresentou os melhores resultados nas análises, embora três marcas tenham apresentado valores de coliformes totais acima do determinado pela legislação.
\end{abstract}

PALAVRAS-CHAVE: Coliformes, instrução normativa $n^{\circ} 51$, qualidade físico-química e microbiológica.

\begin{abstract}
QUALITATIVE EVALUATION OF TYPE A, B AND C PASTEURIZED MILK SOLD IN NATAL, STATE OF RIO GRANDE DO NORTE, BRAZIL. Eight different commercial brands of milk sold in Natal, state of Rio Grande do Norte, Brazil, were sampled and evaluated. Each brand was sampled based on 3 different processing dates, and a total of 24 samples were collected for 1, 3, and 4 brands of type A, B, and C milk, respectively. Analyses were carried out for microbiological measures (total mesophilic aerobic bacteria, total coliforms and thermo-tolerant coliforms) and physicochemical (Ekomilk Total@ ultrasonic milk testing device) determinations were made for fat, nonfat dry extract, density, protein, cryoscopy point, and lactose. The results showed that type A pasteurized milk was the worst in terms of microbiological and physical-chemical properties. Two brands of type B pasteurized milk had microbiological counts violating the law. The type C milk had the best results in this trial although 3 out of 4 brands presented total coliform values above the Brazilian legislation.
\end{abstract}

KEYWORDS: Coliforms, Normative Instruction 51, physical-chemical and microbiological analysis.

A qualidade do leite nos últimos anos vem sendo assunto de grande importância para todos que compõem a cadeia produtiva do leite, no sentido de buscar alternativas que contribuam para melhorias em termos de produtividade e qualidade deste produto, uma vez que o mercado consumidor encontra-se cada dia mais exigente (SiLva et al., 2008).

Oleite, para ser caracterizado como de boa qualidade, deve apresentar as seguintes características: sabor agradável, alto valor nutritivo, ausência de agentes patogênicos e contaminantes (antibióticos, pesticidas, adição de água e sujidades), reduzida contagem de células somáticas e baixa carga microbiana (SANTOS; FonSECA, 2007).

A pasteurização tem como objetivo principal a destruição de micro-organismos patogênicos associados ao alimento. Os produtos pasteurizados podem conter, ainda, muitos organismos vivos capazes de crescer, o que limita sua vida de prateleira. Assim, a pasteurização é, muitas vezes, combinada com outros métodos de conservação como, por exemplo, a refrigeração (PotTer; HоTChKISS, 1995 apud CAMARGO, 2006).

${ }^{2}$ Universidade Federal Rural do Semiárido, Departamento de Ciências Animais, Mossoró, RN, Brasil. 
Objetivou-secomestetrabalhoavaliar a qualidade físico-química e microbiológica do leite pasteurizado tipo A, BeC comercializado na Cidade de Natal, RN.

Foram adquiridas amostras de leite pasteurizado tipo A, B e C de oito diferentes marcas comercializadas na Cidade de Natal com três datas de processamento diferentes, totalizando vinte e quatro amostras. Destas, duas marcas apresentavam Serviço de Inspeção Federal (S.I.F.) e seis, Serviço de Inspeção Estadual (S.I.E.). As amostras foram acondicionadas em caixa isotérmica e levadas ao Laboratório de Inspeção de Produtos de Origem Animal (LIPOA) da Universidade Federal Rural do Semiárido (UFERSA) para análise.

As análises físico-químicas avaliadas foram: gordura, extrato seco desengordurado, densidade, proteína, índice crioscópico e lactose realizada através do aparelho de análise ultrassônica de leite, Ekomilk Total ${ }^{\circledR}$.

Nas análises microbiológicas, as amostras foram diluídas adicionando-se $10 \mathrm{~mL}$ de leite em $90 \mathrm{~mL}$ de água peptonada tamponada $0,1 \%$, sendo esta a diluição $10^{-1}$. Em seguida, foram feitas diluições sucessivas $10^{-2}, 10^{-3} \mathrm{e} 10^{-4}$.

Para a análise de coliformes totais, as amostras foram incubadas em tubos de ensaio com tubo Durhan invertido em caldo verde brilhante a $36 \pm 1^{\circ}$ $C$ por 24 a 48 horas em banho-maria. A presença de coliformes totais era confirmada pela formação de gás no tubo de Durhan e/ou turvação. As amostras positivas para coliformes totais foram replicadas em tubos contendo caldo Escherichia coli, para avaliar se havia coliformes termotolerantes nas amostras. Estes tubos foram incubados a $45 \pm 0,2^{\circ} \mathrm{C}$ por 24 a 48 horas em banho-maria com agitação. A presença de coliformes termotolerantes foi confirmada pela formação de gás ou turvação (BRASIL, 2003).

A contagem de bactérias aeróbias mesófilas foi realizada por profundidade, em duplicata, utilizando $1 \mathrm{~mL}$ de cada diluição em placa de Petri estéril e 15 $\mathrm{mL}$ de Ágar padrão para contagem (PCA) fundido. As placas foram incubadas invertidas a $36 \pm 1^{\circ} \mathrm{C}$ por 48 horas e a leitura foi feita através da contagem de colônias das placas (BRASIL, 2003).

Tabela 1 - Média dos resultados das análises físico-químicas e padrão da legislação brasileira em amostras de leite pasteurizado tipos A, B e C comercializadas em Natal, RN, 2009.

\begin{tabular}{|c|c|c|c|c|c|c|c|}
\hline Amostra/Tipodeinspeção & Tipo & ${ }^{1}$ GORD & ${ }^{2} \mathrm{ESD}$ & ${ }^{3}$ DENS & ${ }^{4} \mathrm{PROT}$ & ${ }^{5} \mathrm{IC}$ & ${ }^{6} \mathrm{LAC}$ \\
\hline 2/ S.I.E & A & $3,2 \%$ a & $7,7 \%$ * a & 1,027 * a & $2,3 \%$ * a & $-0,484^{\circ} C^{* a}$ & $4,9 \%^{a}$ \\
\hline 1/ S.I.F & B & $3,5 \%$ a & $8,8 \%{ }^{b}$ & $1,032^{\mathrm{b}}$ & $3,1 \% \mathrm{~b}$ & $-0,545^{\circ} \mathrm{C}^{\mathrm{b}}$ & $5,0 \%{ }^{a}$ \\
\hline 6/ S.I.E & B & $2,9 \%$ * a & $8,7 \%$ b & $1,031^{b}$ & $3,4 \% b$ & $-0,529^{\circ} \mathrm{C}^{\mathrm{b}}$ & $5,2 \%^{a}$ \\
\hline 7/ S.I.E & B & $3,0 \%$ a & $8,8 \%$ b & $1,033^{b}$ & $3,2 \% \mathrm{~b}$ & $-0,545^{\circ} \mathrm{C}^{\mathrm{b}}$ & $5,0 \%{ }^{a}$ \\
\hline 3/ S.I.E & $\mathrm{C}$ & $3,6 \%$ a & $9,1 \%$ b & $1,032^{b}$ & $3,4 \%$ b & $-0,568^{\circ} \mathrm{C}^{\mathrm{b}}$ & $5,0 \%{ }^{a}$ \\
\hline 4/ S.I.E & $\mathrm{C}$ & $3,4 \%$ a & $8,7 \%$ b & $1,032^{b}$ & $3,1 \% \mathrm{~b}$ & $-0,544^{\circ} \mathrm{C}^{\mathrm{b}}$ & $4,9 \%{ }^{a}$ \\
\hline 5/ S.I.F & $\mathrm{C}$ & $3,2 \%$ a & $8,3 \% * b$ & $1,031^{b}$ & $2,8 \% * b$ & $-0,518^{\circ} \mathrm{C}^{\mathrm{b}}$ & $4,9 \%{ }^{a}$ \\
\hline 8/ S.I.E & C & $2,5 \%$ *a & $8,9 \%$ b & $1,033^{b}$ & $3,2 \%$ b & $-0,547^{\circ} \mathrm{C}^{\mathrm{b}}$ & $5,0 \%{ }^{a}$ \\
\hline
\end{tabular}

\begin{tabular}{lllllll}
\hline Legislação Brasileira & A, B e C & Mín. 3,0\% & Mín. 8,4\% & 1,028 a 1,034 & Mín. 2,9\% & Máx. $-0,512^{\circ} \mathrm{C}$
\end{tabular}

${ }^{1}$ Gordura; ${ }^{2}$ Extrato seco desengordurado; ${ }^{3}$ Densidade; ${ }^{4}$ Proteína; ${ }^{5}$ Índice Crioscópico; ${ }^{6}$ Lactose.

*Amostras fora dos padrões estabelecidos pela legislação. Médias seguidas de mesma letra não diferem estatisticamente ao nível de $5 \%$ de probabilidade pelo teste de Tukey.

Tabela 2 - Média dos resultados microbiológicos de contagens de bactérias mesófilas aeróbias, coliformes totais e coliformes termotolerantes em amostras de leite pasteurizado comercializadas em Natal, RN, 2009.

\begin{tabular}{lcccc}
\hline Amostra/Tipo de inspeção & Tipo & $\begin{array}{c}\text { Bactérias mesófilas } \\
\text { Log.UFC/Ml }\end{array}$ & $\begin{array}{c}\text { Coliformes totais } \\
\text { Log. NMP/mL }\end{array}$ & $\begin{array}{c}\text { Coliformes termotolerantes } \\
\text { Log.NMP/mL }\end{array}$ \\
\hline 2/S.I.E & $\mathrm{A}$ & $4,6^{* a}$ & $1,4^{* \mathrm{ab}}$ & $0,2^{* \mathrm{ab}}$ \\
1/ S.I.F & $\mathrm{B}$ & $3,9^{\mathrm{a}}$ & $2,7^{* \mathrm{~b}}$ & $0^{\mathrm{b}}$ \\
6/S.I.E & $\mathrm{B}$ & $5,1^{* \mathrm{a}}$ & $1,3^{* \mathrm{~b}}$ & $0,5^{* \mathrm{~b}}$ \\
7/S.I.E & $\mathrm{B}$ & $6,2^{* \mathrm{a}}$ & $1,9^{* \mathrm{~b}}$ & $1^{* \mathrm{~b}}$ \\
3/S.I.E & $\mathrm{C}$ & $4^{\mathrm{a}}$ & $0,4^{* \mathrm{a}}$ & $0^{\mathrm{a}}$ \\
4/S.I.E & $\mathrm{C}$ & $3,4^{\mathrm{a}}$ & $1,9^{* \mathrm{a}}$ & $0^{\mathrm{a}}$ \\
5/S.I.F & $\mathrm{C}$ & $4,4^{\mathrm{a}}$ & $0,3^{\mathrm{a}}$ & $0^{\mathrm{a}}$ \\
8/S.I.E & $\mathrm{C}$ & $4,3^{\mathrm{a}}$ & $0,5^{*}$ & $0^{\mathrm{a}}$ \\
\hline Legislação & $\mathrm{A}$ & $\mathrm{m}=2,7$ & $\mathrm{~m}=1$ & Ausência \\
Legislação & $\mathrm{B}$ & $\mathrm{m}=4,6$ & $\mathrm{~m}=0,3$ & $\mathrm{~m}=0$ \\
Legislação & $\mathrm{C}$ & $\mathrm{m}=5,0$ & $\mathrm{~m}=0,3$ & $\mathrm{~m}=0$ \\
\hline
\end{tabular}

*Amostras fora dos padrões estabelecidos pela legislação.

Médias seguidas de mesma letra não diferem estatisticamente ao nível de $5 \%$ de probabilidade pelo teste de Tukey. 
A análise estatística foi realizada através do Teste de Tukey com 5\% de probabilidade. Os resultados foram comparados através da análise de variância (ANOVA) usando valores na escala logarítmica para que eles pudessem ter uma distribuição normal.

Os resultados físico-químicos foram comparados com a legislação (BRASIL, 2004) e encontram-se na Tabela 1.

Os resultados microbiológicos encontram-se na Tabela 2 e foram comparados com a Instrução Normativa ${ }^{\circ} 51$ (BRASIL, 2004).

A densidade média das amostras analisadas de leite tipo A foi de $1,027 \mathrm{~g} / \mathrm{mL}$ estando fora do determinado pela legislação verificada $(1,028$ a 1,034 $\mathrm{g} / \mathrm{mL}$ ) (BRASIL, 2004). A baixa quantidade de lactose $(4,9 \%)$ pode ser justificada pela alta quantidade de bactéria aeróbias mesófilas na amostra, já que estas utilizam a lactose como substrato para a produção de ácido lático (Pereda et al., 2005). O extrato seco desengordurado e a proteína dessa amostra estavam abaixo do determinado pela legislação (BRASIL, 2004). Foram observadas altas contagens de coliformes totais e termotolerantes, 1,4 Log.NMP/mL e 0,2 Log.NMP/mL, respectivamente. A contagem de mesófilas nesta amostra foi de 4,6 Log.UFC/ mL, bem acima do que a legislação permite (2,7 Log.UFC/mL).

Resultados semelhantes foram relatados por Belmonte; Lago (2004) quando pesquisaram leite pasteurizado integral tipo A comercializado nas cidades de Ribeirão Preto e Sertãozinho, SP, sendo observadas algumas amostras com contagem de mesófilos, coliformes totais e termotolerantes inaceitáveis, e concluíram que esses resultados podem ser reflexo de uma matéria-prima excessivamente contaminada, de uma pasteurização deficiente ou mesmo de uma recontaminação pós-pasteurização. SegundoSilva et al. (2008), os coliformes são destruídos na pasteurização e a presença destes em leite pasteurizado indica a necessidade de uma ação mais efetiva no controle do tempo e temperatura do pasteurizador, na seleção de fornecedores de leite cru ena sanitização de equipamentos que entram em contato com o leite após pasteurização. A presença de coliformes termotolerantes encontrados no leite tipo A torna-o impróprio para consumo.

Para o leite tipo B não foram verificadas alterações em relação às características físico-químicas apresentando-se de acordo com a legislação vigente. Este resultado diferencia do observado por GARRIDO et al. (2001) quando avaliavam a qualidade físicoquímica e microbiológica do leite pasteurizado tipo B proveniente de mini emicrousinas de beneficiamento da região de Ribeirão Preto, SP, onde constataram que este tipo de leite apresentou alterações físicoquímica com maior frequência comparado com o leite tipo C e integral.
Em relação à qualidade microbiológica, o leite tipo B apresentou $66,6 \%$ das amostras em desacordo com a legislação, semelhante ao observado por BARUfFaldi et al. (1984) na Cidade de São Paulo, que encontraram $65 \%$ das amostras de leite pasteurizado tipo B analisadas, com contagem padrão em placas superior a 4,0 $\times 10^{4} / \mathrm{mL}$, significando leite in natura excessivamente contaminado, subpasteurização, contaminação pós-processo ou exposição do produto beneficiado à temperatura superior a $10^{\circ} \mathrm{C}$.

O leite tipo C apresentou 25\% das amostras fora dos padrões físico-químicos em pelo menos uma análise (gordura, extrato seco desengordurado ou proteína). Segundo Silva et al. (2008), os maiores problemas com o leite tipo $\mathrm{C}$ se referem à padronização do teor de gordura, seguido da fraude pela adição de água e, consequentemente, diminuição no extrato seco desengordurado. Mujica et al. (2006), em Palmas, TO, encontraram resultados físico-químicos para leite pasteurizado tipo $\mathrm{C}$ dentro dos padrões estabelecidos pela legislação em vigor.

Embora a média de três marcas do leite tipo C tenham apresentado valor acima do determinado pela legislação para coliformes totais, estas não obtiveram contagem superior à determinada para coliformes termotolerantes. As contagens de mesófilas estiveram dentro do determinado para esse tipo de leite. Belmonte; LAgo (2004), em Ribeirão Preto e Sertãozinho, SP, encontraram todas as amostras de leite pasteurizado tipo $\mathrm{C}$ com contagem aceitável para mesófilos aeróbios, $90 \%$ para coliformes totais e $100 \%$ para coliformes termotolerantes.

Em contrapartida, NASCIMENTO et al. (2007), em Fortaleza, CE, encontraram $76,2 \%$ das amostras de leite tipo C impróprias para o consumo e, destas, $23,9 \%$ foram detectadas contagens de 3,4log. NMP/ $\mathrm{mL}$ para coliformes fecais.

Já SILVA et al. (2008), em Alagoas, analisaram amostras de leite tipo $\mathrm{C}$ e obtiveram resultados com elevada contagem de coliformes a $35^{\circ} \mathrm{C}$, coliformes a $45^{\circ} \mathrm{C}$ e contagem de bactérias mesófilas indicando contaminação após o processamento ou tratamento térmico insuficiente.

O leite pasteurizado tipo $\mathrm{C}$ comercializado na Cidade de Natal, RN, foi o único que apresentou qualidade físico-química e microbiológica em conformidade com os padrões exigidos pela Instrução Normativa $\mathrm{n}^{\circ} 51$.

\section{REFERÊNCIAS}

BARUFFALDI, R.; PENNA, T.C.V.; MACHOSHVILI, I.A.; ABE, L.E. Sanitary condition of "type B" pasteurized milk sold in S. Paulo city, SP (Brazil) in the period from February to August, 1982. Revista Saúde Pública, v.18, n.5, 8p. 1984. 
BELMONTE, E. A.; LAGO, N. C. M. R. Pesquisa de microrganismos indicadores em leite pasteurizado integral comercializado nas cidades de Ribeirão Preto e Sertãozinho, SP. In: CONGRESSO BRASILEIRO DE QUALIDADE DO LEITE, 1., 2004, Passo Fundo, RS. Resumos. Passo Fundo: Universidade de Passo Fundo, 2004. 3p.

BRASIL. Ministério da Agricultura, Pecuária e Abastecimento. Análises microbiológicas para controle de produção de origem animal e água: Instrução normativa $n^{\circ}$ 62. Brasília: MAPA, 2003. 205p.

BRASIL. Ministério da Agricultura, Pecuária e Abastecimento. Leite: Instrução Normativa $n^{\circ} 51$ de 18 de setembro de 2002. Brasília: MAPA/SE, 2004. 95p.

CAMARGO, A.C. Conservação pelo calor. 2006. Disponível em: <http:/ / www.cena.usp.br/irradiacao/ cons_calor.htmL>. Acesso em: 22 mai. 2009.

GARRIDO, N.; MORAIS, J.M.T.; BRIGANTI, R.C.; OLIVEIRA, M.A.; BERGAMINI, A.M.M.; OLIVEIRA, S.A.V.; FÁVARO, R.M.D. Avaliação da qualidade físico-química e microbiológica de leite pasteurizado proveniente de mini e micro-usinas de beneficiamento da região de Ribeirão Preto, São Paulo. Revista Instituto Adolfo Lutz, v.60, n.2, p.141-146, 2001.

MUJICA, P.Y.C.; ANJOS, E.S.; CARNEIRO, P.H.; SALES, P.V.G.; SILVA, J.V.G.; COSTA, J. C. D. P. P. Avaliação da qualidade físico-química do leite pasteurizado tipo " $\mathrm{C}$ " comercializado no município de Palmas - TO. In: CONGRESSO BRASILEIRO DE QUALIDADE DO LEITE, 2., 2006, Goiânia, GO. Resumos. Goiânia: CBQL, 2006. 2p.

NASCIMENTO, K.M.; AMORIM, L.N.; UNHA, F.A.; SOUSA, G.C.; SANTOS, R.S.; SOARES, K.P.; LIMA NETO, J.G.; MENDES, L.G.; MENEZES, E.A. Qualidade
Microbiológica do leite pasteurizado tipo B e C comercializado na cidade de Fortaleza. In: CONGRESSO BRASILEIRO DE QUÍMICA, 47., 2007, Natal, RN. Resumos. Natal, RN: CBQ, 2007.1p.

PEREDA, J.A.O.; RODRIGUEZ, M.I.C.; ÁLVAREZ, L.F.; SANZ, M.L.G.; MINGUILLÓN, G.D.G.F.; PERALES, L.H.; CORTECERO, M.D.S. Tecnologia de alimentos. Traduzido por Fátima Murrad. Porto Alegre: Artmed, 2005. v.2, 279p.

SANTOS, M.V.; FONSECA, L.F.L. Qualidade microbiológica do leite: métodos de análise e estratégias de controle. Monitoramento da qualidade do leite: módulo 2. Curso online. São Paulo: Faculdade de Medicina veterinária e Zootecnia, Universidade de São Paulo, 2004. 15p.

SANTOS, M.V.; FONSECA, L.F.L. Estratégias para controle de mastite e melhoria da qualidade do leite. Barueri, SP: Manole, 2007. 314p.

SILVA, A.M.; MODESTO, E.C.; LIRA, C.C.; SANTOS, M.V.F.; JATOBÁ, R.B. Contagem de células somáticas e composição do leite de vacas Girolanda na região da zona da mata pernambucana. In: CONGRESSO BRASILEIRO DE QUALIDADE DO LEITE, 3., 2008, Recife, PE. Resumos. Recife: CCS, 2008. 3p.

SILVA, M.C.D.; SILVA, J.V.L.; RAMOS, A.C.S.; MELO, R.O.; JULIANA, O.O. Caracterização microbiológica e físico-química de leite pasteurizado destinado ao programa do leite no Estado de Alagoas. Ciência e Tecnologia de Alimentos, v.28, n.1, p.226-230, 2008.

Recebido em 5/5/11

Aceito em 4/5/12 